\title{
Magnetohydrodynamic Flow and Heat Transfer Over an Exponentially Stretching/Shrinking Sheet in Ferrofluids
}

\author{
Nurfazila Rasli and Norshafira Ramli* \\ School of Mathematical Sciences, Universiti Sains Malaysia, 11800 USM, Penang, Malaysia
}

\begin{abstract}
In this research, the problem of magnetohydrodynamic flow and heat transfer over an exponentially stretching/shrinking sheet in ferrofluids is presented. The governing partial differential equations are transformed into nonlinear ordinary differential equations by applying suitable similarity transformations. These equations are then solved numerically using the shooting method for some pertinent parameters. For this research, the water-based ferrofluid is considered with three types of ferroparticles: magnetite, cobalt ferrite, and manganese-zinc ferrite. The numerical solutions on the skin friction coefficient, Nusselt number, velocity and temperature profiles influenced by the magnetic parameter, wall mass transfer parameter, stretching/shrinking parameter, and volume fraction of solid ferroparticle are graphically displayed and discussed in more details. The existences of dual solutions are noticeable for the stretching/shrinking case in a specific range of limit.
\end{abstract}

For the first solution, an increasing number in magnetic and suction will also give an

ARTICLE INFO

Article history:

Received: 9 February 2021

Accepted: 22 April 2021

Published: 31 July 2021

DOI: https://doi.org/10.47836/pjst.29.3.42

E-mail addresses:

nurfazilarasli17@gmail.com (Nurfazila Rasli)

norshafiraramli@usm.my (Norshafira Ramli)

*Corresponding author increment of skin friction coefficient and Nusselt number over stretching/shrinking sheet. For the skin friction coefficient only, it is showed a decreasing pattern after the intersection. Besides, the presence of ferroparticles in the fluids causes a high number of the fluid's thermal conductivity and heat transfer rate.

Keywords: Ferrofluids, heat transfer, magnetohydrodynamic, stretching/shrinking 


\section{INTRODUCTION}

Nanofluid is a fluid that consists of small quantities of nanometer-size (usually less than $100 \mathrm{~nm}$ ) particles known as nanoparticles. Choi and Eastman (1995) reported nanoparticles are a new way of how heat move the fluids, which show engineered colloids consist of nanoparticles by dispersing in conventional heat transfer fluids. Tiwari and Das (2007) have initiated a model to investigate the characteristics of nanoparticles. Within two-sided liddriven, there are nanoparticles with a disparately heated square cavity. The effects showed the ability of heat transport might be increased when nanoparticles are mixed with the fluid. These nanoparticles are steadily dispersed and have potential as an efficient heat transport agent because of the more considerable value of thermal conductivity (Muthtamilselvan et al., 2010).

Besides, there is a magnetic nanofluid known as ferrofluid which is composed of magnetic nanoparticles. The example of ferrofluids is hematite and magnetite. Besides, ferrofluid is useful since it has a flexible functioning in the existence of a magnetic field. It had drawn the researchers' attention due to a lot of applications in cooling of loudspeakers, mechanoelectrical areas and biomedical sections (magnetic resonance tomography, drug delivery, cancer treatment and improvement of magnetic resonance image) (Odenbach, 2003; Blaney, 2007; Shokrollahi, 2013). Ferrofluid also has exhilarating present real-world applications. An extensive advantage is that the liquid can be forced to flow by way of the positioning and vitality of the magnetic field so that the ferrofluid can be arranged very accurately. Ferrofluids have the capability of reducing friction, making them useful in a variety of electronic and transportation applications. The additional different fields in which ferrofluids can be applied are heat transfer, aerospace, and art.

Bhattacharyya (2011) has reported a very systematic method known as the shooting technique to solve the problem of heat transfer. This problem is focused on the twodimensional flow of Newtonian fluid. This analysis showed that when the parameter of mass suction goes over the limit, the flow is stable because of the exponential shrinking sheet. Then, other achievements have been obtained in both solutions for velocity and temperature profiles. Higher number of mass suction in the first solution caused a rising number in skin friction while decreasing in the second solution. According to Bhattacharyya and Vajravelu (2012), they focused on the shrinking layer which is boundary layer stagnationpoint flow and heat transport. Resolving the problem, similarity equations and shooting technique have been applied. They found a small number of similarity solutions obtained in linear shrinking sheet case compared to exponentially shrinking case. When the straining rate is more extensive than the shrinking rate, dual solutions exist with some conditions and the capability of heat absorption may be possible happen. Research of three preferred nanofluids such as copper, alumina, and titania with Prandtl number $\operatorname{Pr}=6.2$ has been considered by Bachok et al. (2012) and heat transfer rate by using the shooting method. 
They found that the similarity solution for exponentially stretching/shrinking sheet occurs higher for the linear case. A non-unique solution exists for the shrinking sheet while differ from the stretching part. Then, an increasing value of skin friction and heat movement due to insertion nanoparticles into water-based fluid. Finally, they found the most significant value of skin friction and Nusselt number is copper. Nadeem et al. (2014) researched about nanoparticles specifically in water-based heat transfer at the exponentially stretching sheet. A variety of governing parameters such as temperature, stretching and volume fraction are analyzed to see the effect on the profiles, the physical quantities and heat transfer rate. Runge Kutta $4^{\text {th }}$ order and shooting method are used to determine the ordinary differential equations. They analyzed the temperature profiles increased when the nanofluid volume fraction increases. Then, increasing in stretching parameter also increasing in the skin friction coefficient and rate of heat transmission. Resistance copper absorption in the fluid is higher than titanium dioxide and alumina, which are the same results with the previous study as mentioned above.

Recently, in magnetic fields, many researchers study how the fluid is conducted electrically and the heat transfer of viscous fluid along the surface. A study by Noghrehabadi et al. (2014) found varieties of applications in magnetohydrodynamic (MHD) flow in the engineering and industrial. Bhattacharyya and Pop (2011) have studied the exponentially shrinking sheet along with magnetohydrodynamic movement. By implementing the shooting method, they found how the separation of the boundary layer is delayed. It happened because of the suppression of Lorentz force on the vorticity produced due to the shrinking sheet. An increasing magnetic field also affected the steady outflow of the exponential shrinking layer and produced a lesser amount of wall mass suction. Two different solutions also achieved for the flow field in a particular case. Using the Keller-box method, Ishak (2011) studied a problem of radiation effect on stretching sheet exponentially with magnetohydrodynamic layer flow. He discovered that bigger number of radiation and magnetic existing the regional heat of lower rate. Then, Bhattacharyya and Layek (2014) investigated the porous sheet with the consequence of flow in the magnetohydrodynamic boundary layer of nanofluid. By applying the shooting method, they noted a more significant number in volume fraction of nanofluids and temperature occur because of the magnetic. Besides, due to the exponential stretching sheet, the magnetic field decreased the heat transfer rate. Apart from that, the volume fraction of nanoparticles and temperature inside the boundary layer seemed to increase as a result of this magnetic region. The thickness of the velocity boundary layer becomes thinner due to the mass suction, whereas thicker in the injection case. Alavi et al. (2017) have reported the problem of stretching sheet exponentially over wall temperature, heat flux and magnetohydrodynamic stagnation point flow. The problem is to work out numerically with a method known as Keller-box. An increase in magnetic parameter also increased the velocity. Besides, this happened because 
of the existence of wall temperature and heat flux too. Jusoh et al. (2018) have reviewed porous layer stretching/shrinking exponentially and solved by $b v p 4 c$ function known as the finite-difference code of Matlab solver. They found that suction in boundary condition has shown the surface is permeable and dual solutions had occurred in a particular region of the shrinking sheet problem. Higher magnetic parameter increased induced Lorentz force and decreased the momentum within the layer.

Another study, Mansur et al. (2015) have reviewed studies on the influence of suction on magnetohydrodynamic stagnation point flow in nanofluid over a stretching/shrinking sheet. By applying $b v p 4 c$ function from Matlab, they concluded that the first and second solutions existed in shrinking. However, a special solution exists in the stretching case only. An increase of suction and magnetic field will also increase the stability of the skin friction while the heat transfer rate decreases due to the Brownian parameter and thermophoresis parameter. Then, the investigation of the consequence of injection/suction for magnetohydrodynamic flow throughout a porous stretching/shrinking sheet of nanofluids has been found by Naramgari and Sulochana (2016). They noticed for certain parameters; the dual solutions only happen for some range. In the stretching surface, the heat transfer rate is reduced because the magnetic field even the stretching/shrinking and injection/suction parameters can increase the enhancement of heat transfer. Ramli et al. (2018) reported the reaction of uniform heat change and second-order slip on magnetohydrodynamic flow involving the forced convection and a moving plate to study the motion of heat in ferrofluids. They analyzed how the skin friction, Nusselt number, velocity, and temperature affected by the parameter of magnetic, moving, mass transfer, first-order surface slip, second-order surface slip and volume fraction of solid ferroparticles in the form of tabular and graphical presentations by using the shooting method. The final discussion shows that ferrofluids base fluid produced the smallest skin friction and local Nusselt number than kerosene-based ferrofluids in both results. Thus, it delayed the separation of the boundary layer when the volume fraction of ferrofluids combined with the effects of the magnetic, moving, mass transfer, and slip parameters. A problem of linearly stretching/shrinking sheet in nanofluids involving the stagnation-point of magnetohydrodynamic motion has been investigated by Rahman et al. (2019). The titania, alumina and copper are metallic nanoparticles that are used to analyze the volume fraction parameter of the nanoparticles in water with the Prandtl number=6.2. In solving boundary value problems, the function of $b v p 4 c$ from Matlab has been used due to its effectiveness. The final solution shows that the magnetic field and nanoparticles volume fraction will affect the momentum and temperature. Apart from that, non-unique results of dual solutions only obtained for the shrinking sheet case while different results for the stretching sheet case. Then, Mohamed et al. (2019) have reported the impact of Newtonian heating on magnetite. They applied 
Runge-Kutta-Fehlberg to calculate numerically, and the final solutions shown the magnetite ferrofluid provided greater value for the heat transfer and temperature of the wall than water.

According to the literature, many researchers have attempted the problem of magnetohydrodynamic flow and heat transfer but not specifically in the ferrofluids. In this paper, we want to study the magnetohydrodynamic flow and heat transfer over an exponentially stretching/shrinking sheet in ferrofluids. This research is related to the Tiwari and Das' model. Thus, to interpret the ordinary differential equation, a shooting technique will be applied with the similarity variation. Then, it is resolved numerically and, the numerical results are discussed in detail and plotted graphically.

\section{MATERIALS AND METHOD}

\section{Basic Equations}

This problem is related with three preferred ferrofluids of magnetohydrodynamic boundary layer flow. The flow is in steady and laminar case. Due to the magnetic field, heat motion over an exponentially stretching/shrinking sheet, have been studied. The supposed temperature of boundary layer of the sheet is $T_{w}=T_{\infty}+T_{0} e^{x / 2 L}$ where $T_{w}$ is the sheet's temperature variable, $T_{\infty}$ is the free stream temperature predicted to be persistent and $T_{0}$ is an ambient temperature to calculate temperature's rate which increase along the surface of the layer. We noted $U_{w}(x)=a e^{x / L}$ is the stretching/shrinking velocity where, $a$ is the velocity rate of stretching/shrinking with $a>0$ for stretching, $a<0$ for shrinking and $L$ is the reference velocity. The physical models and coordinate system are pictured in Figure 1.

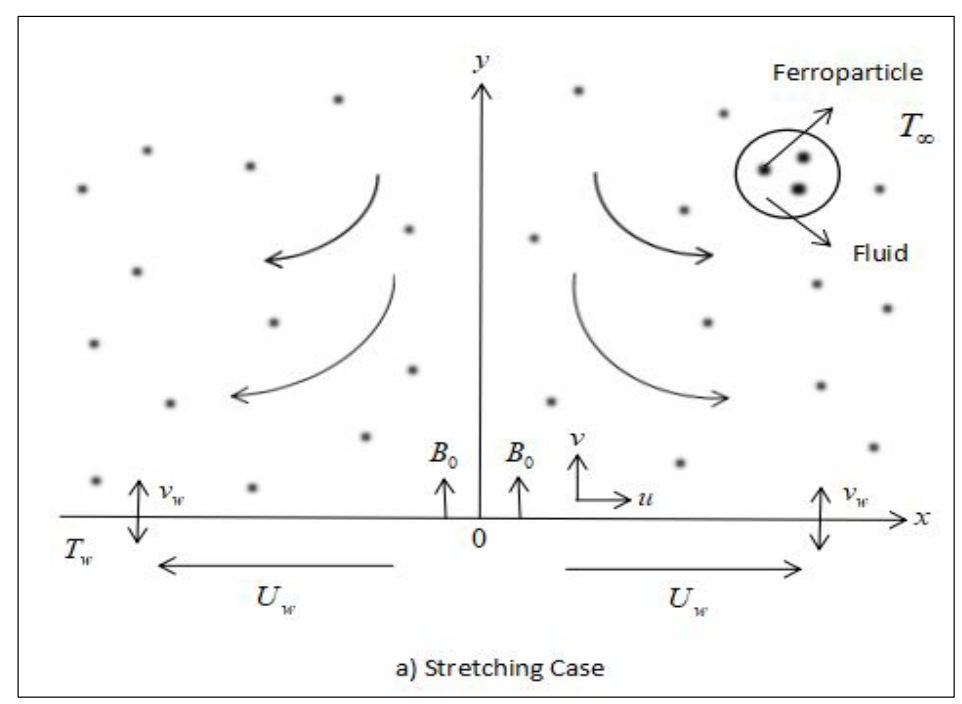




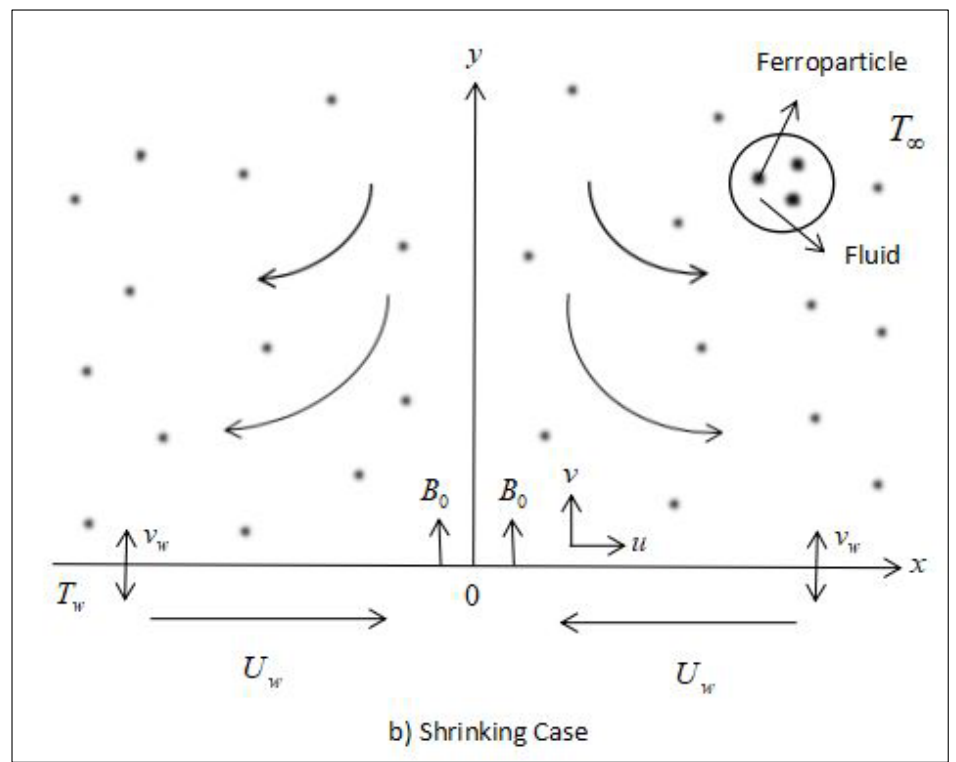

Figure 1. Physical models and coordinate system for stretching and shrinking cases

Basic equations are assumed and under consideration are as follows (Equations 1, 2 \& 3) (Bhattacharrya \& Pop, 2011; Magyari \& Keller,1999):

$$
\begin{aligned}
& \frac{\partial u}{\partial x}+\frac{\partial v}{\partial y}=0 \\
& u \frac{\partial u}{\partial x}+v \frac{\partial v}{\partial y}=v_{f f} \frac{\partial^{2} u}{\partial y^{2}}-\frac{\sigma B^{2}}{\rho_{f f}} u \\
& u \frac{\partial T}{\partial x}+v \frac{\partial T}{\partial y}=\alpha_{f f} \frac{\partial^{2} T}{\partial y^{2}}
\end{aligned}
$$

with the following boundary conditions (Equation 4)

$$
\begin{gathered}
u=\lambda U_{w}(x), v=v_{w}, T=T_{w}, \text { at } y=0, \\
u \rightarrow 0, T \rightarrow T_{\infty}, \text { as } y \rightarrow \infty,
\end{gathered}
$$

where $u$ and $v$ are the elements of velocity along the $x$ - and $y$-axes, $\sigma$ is an electrical conductivity, $B$ is the total magnetic field, $\lambda$ is the stretching/shrinking parameter, $\sigma$ is an electrical conductivity, $T$ is the temperature, and $v_{w}$ is the variable wall mass transfer velocity. Here, $v_{f f}$ denotes the kinematic viscosity of the ferrofluid, $\alpha_{f f}$ is the thermal diffusivity of the ferrofluid and $\alpha_{f f}$ is the density of the ferrofluid, which are defined as Equation 5: 


$$
\begin{gathered}
v_{f f}=\frac{\mu_{f f}}{\rho_{f f}}, \mu_{f f}=\frac{\mu_{f}}{(1-\varphi)^{2.5}}, \alpha_{f f}=\frac{k_{f f}}{\left(\rho C_{p}\right)_{f f}}, \rho_{f f}=(1-\varphi) \rho_{f}+\varphi \rho_{s}, \\
\left(\rho C_{p}\right)_{f f}=(1-\varphi)\left(\rho C_{p}\right)_{f}+\varphi\left(\rho C_{p}\right)_{s}, \frac{k_{f f}}{k_{f}}=\frac{\left(k_{s}+2 k_{f}\right)-2 \varphi\left(k_{f}-k_{s}\right)}{\left(k_{s}+2 k_{f}\right)+\varphi\left(k_{f}-k_{s}\right)},
\end{gathered}
$$

where $\mu_{f f}$ is ferrofluid's viscosity, $\mu_{f}$ is fluid's viscosity, $\varphi$ is defined as volume fraction of ferroparticle, $\left(\rho C_{p}\right)_{f f}$ is ferrofluid's heat capacity, $k_{f f}$ is ferrofluid's thermal conductivity, $k_{f}$ is fluid's thermal conductivity and $k_{s}$ is solid fraction's thermal conductivity while $\rho_{f}$ and $\rho_{s}$ are the densities of the fluid and of the solid fractions, respectively. The magnetic field $B(x)$ is defined as $B(x)=B_{0} e^{x / 2 L}$, where $B_{0}$ denotes a constant magnetic field. Then, $v_{w}$ is considered to be the velocity of wall mass transfer and is presented by $v_{w}=v_{0} e^{x / 2 L}$, where $v_{0}<0$ for mass suction and $v_{0}>0$ for mass injection.

By introducing the following similarity transformation, the easier step can be shown by using Equation 1-3 with the subjected boundary conditions as in Equation 4 is defined as Equation 6:

$$
\eta=y\left(\frac{a}{2 v_{f} L}\right)^{1 / 2} e^{x / 2 L}, \psi=\left(2 v_{f} L a\right)^{1 / 2} f(\eta) e^{x / 2 L}, \theta(\eta)=\frac{T-T_{\infty}}{T_{w}-T_{\infty}},
$$

where $\eta$ is the similarity variables, $v_{f}$ is the fluid's kinematic viscosity and $\psi$ is the stream function which can be specified as $u=\partial \psi / \partial y$ and $v=\partial \quad \psi / \partial x$. By employing Equation 6, Equation 2 and 3 will take the consecutive form of Equations 7 and 8, respectively.

$$
\begin{gathered}
\frac{1}{(1-\varphi)^{2.5}\left[(1-\varphi)+\varphi \rho_{s} / \rho_{f}\right]} f^{\prime \prime \prime}+f f^{\prime \prime}-2 f^{\prime 2}-M f^{\prime}=0, \\
\frac{1}{\operatorname{Pr}} \frac{k_{f f} / k_{f}}{\left[1-\varphi+\varphi\left(\rho C_{p}\right)_{s} /\left(\rho C_{p}\right)_{f}\right]} \theta^{\prime \prime}+f \theta^{\prime}-f^{\prime} \theta=0,
\end{gathered}
$$

which primes represent the differentiation of $\eta, \quad M=2 \sigma B_{0}{ }^{2} L / \rho_{f} a$ is the magnetic parameter, $\operatorname{Pr}=\left(\mu C_{p}\right)_{f} / k_{f}$ is the Prandtl number.

The transformation of boundary conditions is defined in Equation 9.

$$
\begin{gathered}
f(0)=S, f^{\prime}(0)=\lambda, \theta(0)=1, \\
f^{\prime}(\eta) \rightarrow 0, \theta(\eta) \rightarrow 0, \text { as } \eta \rightarrow \infty,
\end{gathered}
$$

where the wall mass transfer parameter is defined as $S$ in which mass suction is $S<0$. and mass injection is $\lambda<0$ Then stretching/shrinking parameter can be divided into two cases which are $\lambda<0$ for a shrinking sheet and $\lambda>0$ for a stretching sheet.

Next, the skin friction coefficient $C_{f}$ and local Nusselt number $N u_{x}$ are known as the physical quantities and are defined as Equation 10. 


$$
C_{f}=\frac{\tau_{w}}{\rho_{f} U_{w}{ }^{2}}, N u_{x}=\frac{x q_{w}}{k\left(T_{w}-T_{\infty}\right)},
$$

while $\tau_{w}$ is the shear stress and $q_{w}$ is the surface heat flux shown as in Equation 11.

$$
\tau_{w}=\mu_{f f}\left(\frac{\partial u}{\partial y}\right)_{y=0}, q_{w}=-k_{f f}\left(\frac{\partial T}{\partial y}\right)_{y=0},
$$

Where, $\mu_{f f}$ is the dynamic viscosity and $k_{f f}$ is thermal conductivity of the ferrofluids, respectively. Similarity variables in Equation 6 are applied to obtain Equations 12 and 13.

$$
\begin{aligned}
& \operatorname{Re}_{x}{ }^{1 / 2} C_{f}=\frac{1}{(1-\varphi)^{2.5}} f^{\prime \prime}(0), \\
& \operatorname{Re}_{x}^{-1 / 2} N u_{x}=-\frac{k_{f f}}{k_{f}} \theta^{\prime}(0),
\end{aligned}
$$

In which $\operatorname{Re}_{x}=U_{w} L / v_{f}$ is the Reynolds number.

\section{RESULT AND DISCUSSION}

There is a function of shootlib in Maple software which applicable to run the shooting technique to solve Equations 7 and 8 under Equation 9. For this study, the governing ordinary differential equations must be converted into an initial value problem with the aid of Runge Kutta 4th order method. Besides, we need to guess some of the initial value for physical parameters to determine the missing value of $f^{\prime \prime}(0)$ and $\theta^{\prime}(0)$. The finite number of boundary layer thickness $\eta \rightarrow \infty$, namely $\eta_{\infty}$ must be chosen and for this study, $\eta_{\infty}=10$ is used. Newton-Raphson method is required to iterate the correct guessed of initial number until convergence is satisfied. In this problem, Newton's method is used to estimate the skin friction and local Nusselt until the results approach zero with the desired efficiency of $10^{-9}$. For this study, the dual solutions and all profiles are obtained to satisfy boundary conditions in Equation 9, yet various pattern displays.

The influence of the magnetic parameter, $M$, stretching/shrinking parameter, $\lambda$, mass transfer parameter, $S$, and volume fraction of solid ferroparticles, $\varphi$ on the skin friction coefficient, $\operatorname{Re}_{x}{ }^{1 / 2} C_{f}$, Nusselt numbers, $\operatorname{Re}_{x}^{-1 / 2} N u_{x}$, velocity, $f(\eta)$ and temperature $\theta(\eta)$ were examined. This research involves three preferred ferroparticles which are magnetite, cobalt ferrite, and manganese-zinc ferrite in water-based fluid with $\operatorname{Pr}=6.2$. In addition, the volume fraction of solid ferroparticles $\varphi$ is considered between scale of the $0 \leq \varphi \leq 0.2$, where the pure water is presented by $\varphi=0$.

Table 1 shown the data of the base fluids and the following ferroparticles about thermophysical properties which are found from Khan et al. (2015). Besides, to prove 
the validity of the current method, the numerical solutions of the local heat $-f^{\prime \prime}(0)$ are differentiated with those studied by Magyari and Keller (1999) and Bhattacharyya and Layek (2014), as shown in Table 2. Compared to the previous study by Magyari and Keller (1999), their study was performed without the presence of a magnetic field and over exponentially stretching sheet only. Thus, we extend the problem with the presence of magnetic field to observe how the magnetic field will affect the flow/motion of the fluid in the boundary layer over exponentially stretching and shrinking sheets. Then, this present study is also compared to another previous study by Bhattacharyya and Layek (2014). We choose the Prandtl number to be fixed and without the presence of the Lewis number, Brownian motion parameter and thermophoresis parameter effect. The present results are found to be in excellent agreement with the published data and thus gives us some confidence in the present numerical results.

Table 1

Thermophysical properties of fluid and magnetic ferroparticles (Khan et al., 2015)

\begin{tabular}{lccccc}
\hline \multirow{2}{*}{$\begin{array}{l}\text { Physical } \\
\text { Properties }\end{array}$} & Base Fluid & & \multicolumn{3}{c}{ Magnetic nanoparticles } \\
\cline { 2 - 2 } \cline { 5 - 6 } \cline { 5 - 6 }$\left(\mathrm{kg} / \mathrm{m}^{3}\right)$ & Water & & $\mathrm{Fe}_{3} \mathrm{O}_{4}$ & $\mathrm{CoFe}_{2} \mathrm{O}_{4}$ & $\mathrm{Mn}^{2} \mathrm{ZnFe}_{2} \mathrm{O}_{4}$ \\
$C_{p}(\mathrm{j} / \mathrm{Kg} . \mathrm{k})$ & 497 & & 5180 & 4907 & 4900 \\
$k(\mathrm{~W} / \mathrm{m} . \mathrm{k})$ & 0.613 & & 670 & 700 & 800 \\
\hline
\end{tabular}

Table 2

Values of $-f$ "'(0) for $M=0$ when $\lambda=1, S=0$ and $\varphi=0$.

\begin{tabular}{llll}
\hline & $\begin{array}{l}\text { Magyari and Keller } \\
(1999)\end{array}$ & $\begin{array}{l}\text { Bhattacharyya and Layek } \\
(2014)\end{array}$ & Present study \\
\hline$-f^{\prime \prime}(0)$ & 1.281808 & 1.2810838 & 1.28182804 \\
\hline
\end{tabular}

Figures 2-7 represent the different values of $M, S$ and $\varphi_{\text {when Prandtl number is }}$ 6.2. Figures 2-7 demonstrate the effects of skin friction coefficient, and Nusselt number with stretching and shrinking parameter, $\lambda$ wall mass transfer $S$ and ferroparticle volume fraction $\varphi$. 


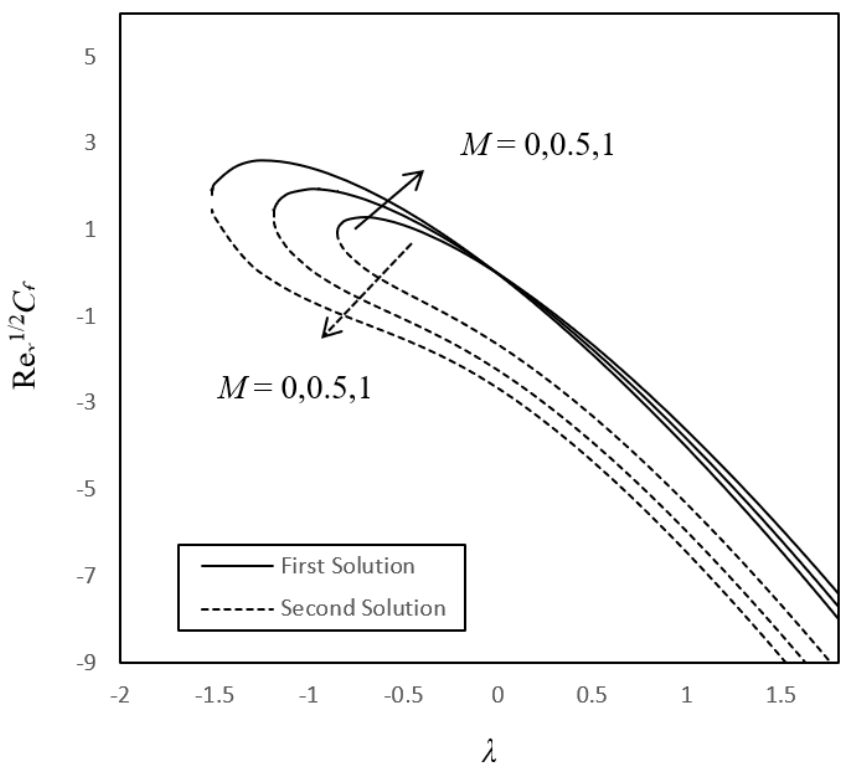

Figure 2. Effects of $M$ on skin friction coefficient with $S=2$ and $\varphi=0.1$.

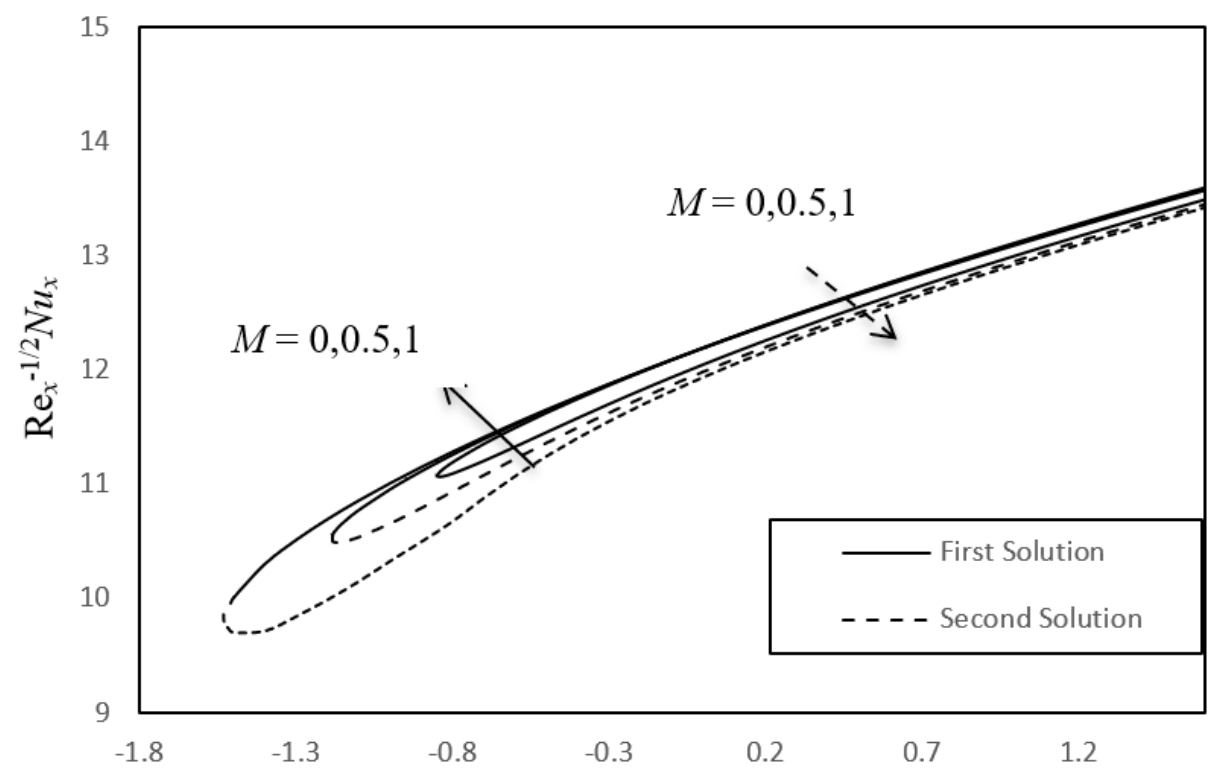

Figure 3. Effects of $M$ on Nusselt number with $S=2$ and $\varphi=0.1$. 


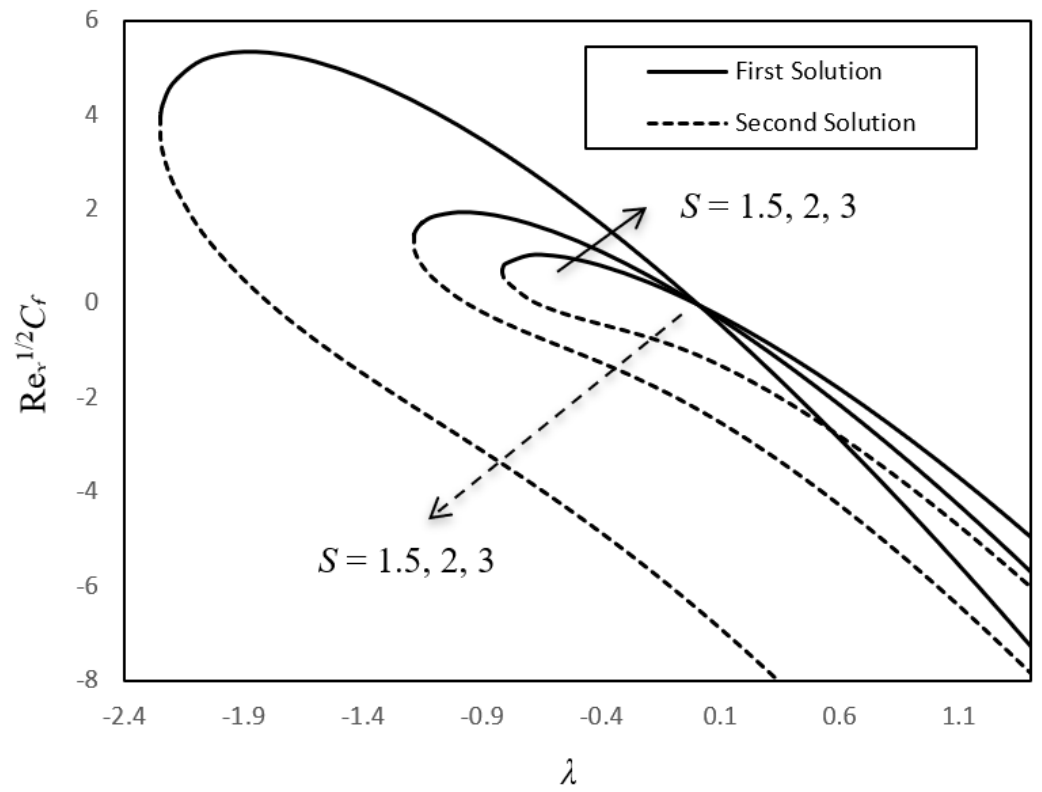

Figure 4. Effects of $S$ on skin friction coefficient with $M=0.5$ and $\varphi=0.1$.

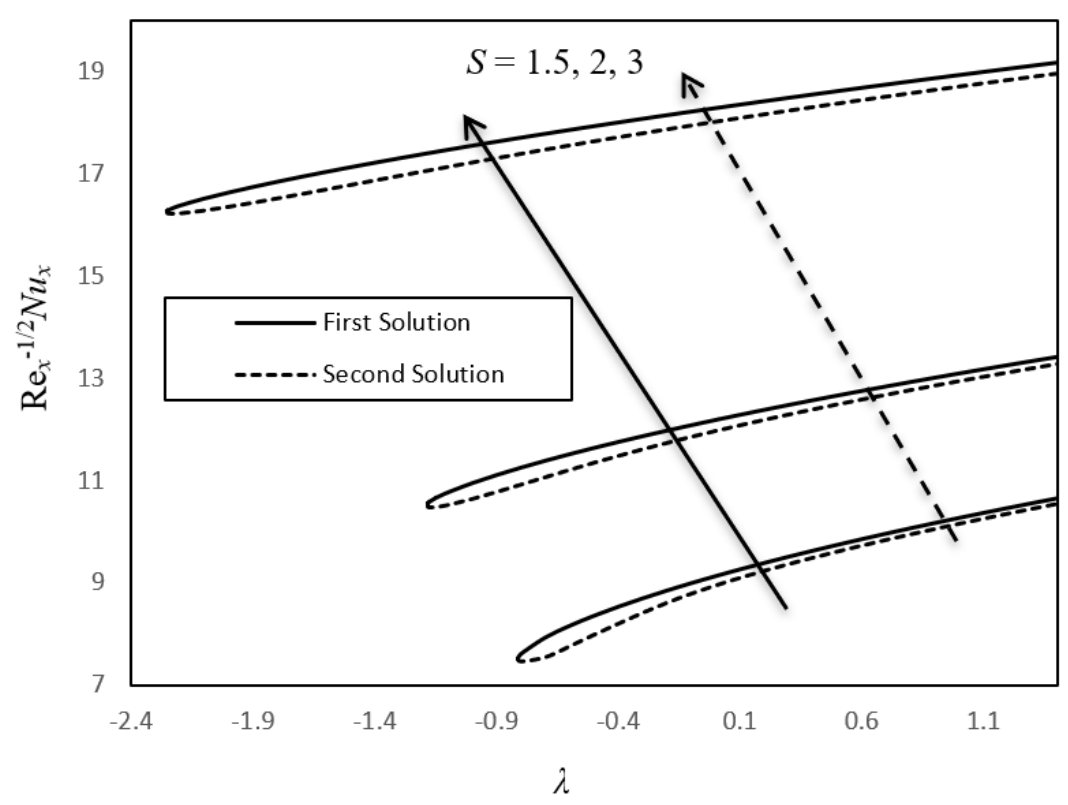

Figure 5. Effects of $S$ on Nusselt number with $M=0.5$ and $\varphi=0.1$. 


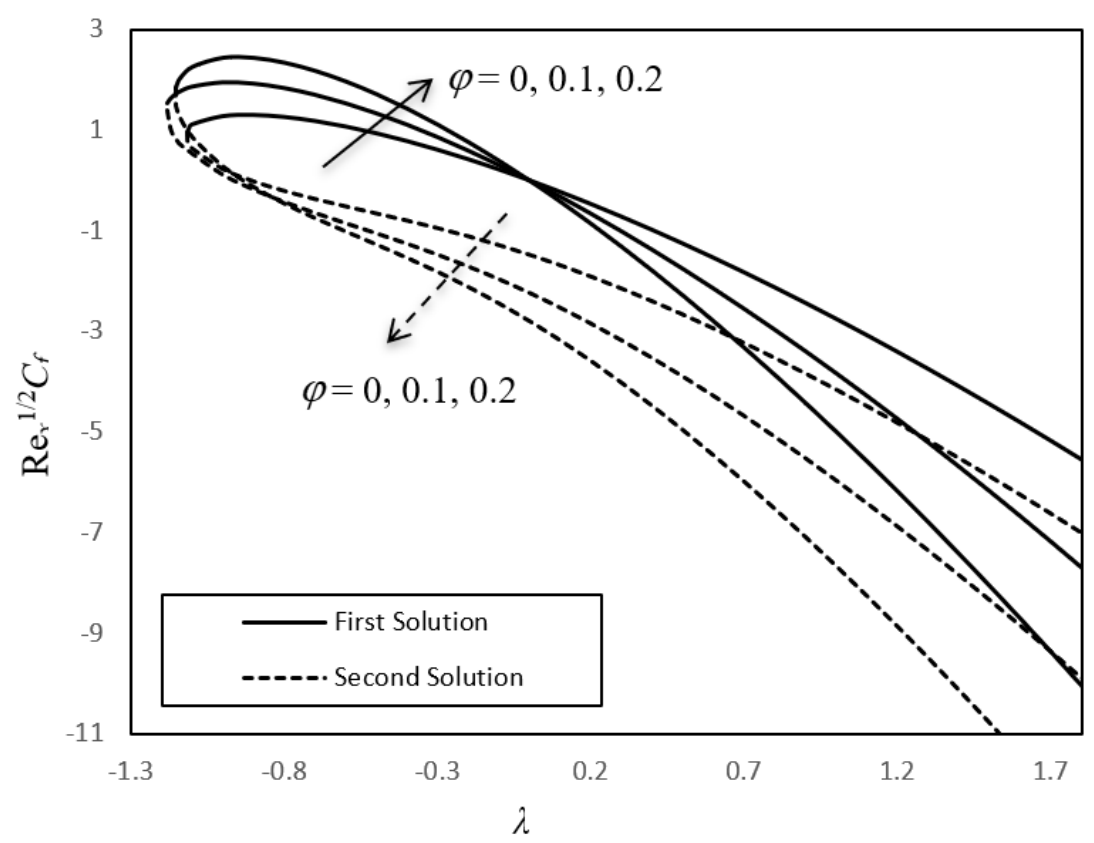

Figure 6. Effects of $\varphi$ on skin friction coefficient with $M=0.5$ and $S=2$.

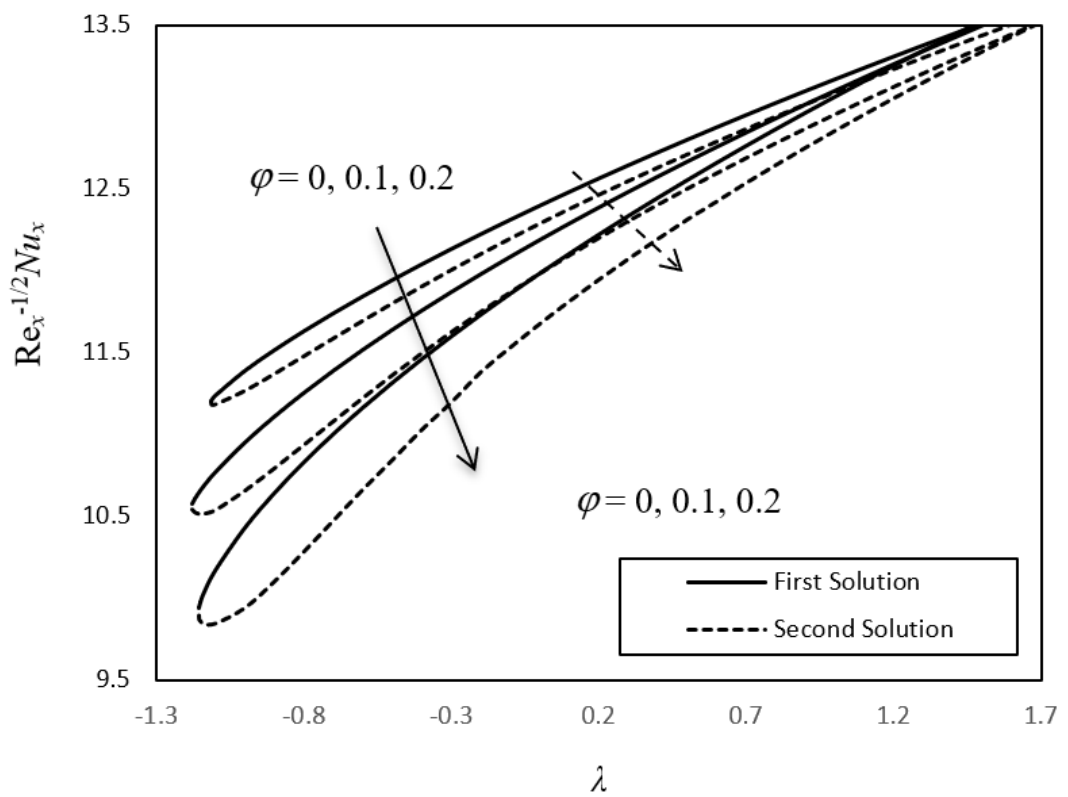

Figure 7. Effects of $\varphi$ on Nusselt number with $M=0.5$ and $S=2$. 
Based on Figures 2-7, we analyzed that there are the first and second solution have occurred in the chosen parameters. Clearly, we can see the solid lines and dash lines which symbolize as the first and second solution, respectively. For this dual solutions, it is seemed that there is no solution when $\lambda<\lambda_{\mathrm{c}}$ or $S<S_{\mathrm{c}}$ or $\varphi<\varphi_{\mathrm{c}}$. This process may affect the boundary layer which help in delaying the boundary layer separation.

On the other hand, we can point out a further discussion for the first solution of Figure 2-7 by considering the first solution is stable and physically realizable. It is found that the magnetic parameter $M$, mass transfer parameter $S$, and volume fraction of solid ferroparticles $\varphi$, help to enhance the skin friction coefficient and Nusselt number.

Table 3 and 4 display variants of Nusselt number, $\operatorname{Re}_{x}^{-1 / 2} N u_{x}$ and skin friction coefficient, $\operatorname{Re}_{x}^{1 / 2} C_{f}$ of magnetic $M$ in water-based ferrofluids when $\lambda=-0.5, \varphi=0.1, \operatorname{Pr}=6.2$, and $S$ $=2$. From Table 3 , which is in shrinking case $\lambda<0, \mathrm{Fe}_{3} \mathrm{O}_{4}$ seems to have higher values of skin friction coefficient compared to other ferrofluid mixture. Then, Table 4 presents that $\mathrm{CoFe}_{2} \mathrm{O}_{4}$ have greater value of local Nusselt number. Through Table $1, \mathrm{CoFe}_{2} \mathrm{O}_{4}$ has a small number of thermal conductivities compared with $\mathrm{Fe}_{3} \mathrm{O}_{4}$, reduction of thermal conductivity of $\mathrm{CoFe}_{2} \mathrm{O}_{4}$ may show to a greater value of temperature gradients and may increase the results of the enhancement in heat transfers. We can see that $\mathrm{Fe}_{3} \mathrm{O}_{4}$ has the highest thermal conductivity among the two ferrofluids. Even though $\mathrm{Fe}_{3} \mathrm{O}_{4}$ has higher thermal conductivity, temperature gradients decreased and influenced the behaviour of the $\mathrm{Fe}_{3} \mathrm{O}_{4}$.

Table 3

Values of $\mathrm{Re}_{x}^{1 / 2} C_{f}$ with different values of $M$

\begin{tabular}{llcc}
\hline $\begin{array}{l}\text { Magnetic } \\
\text { nanoparticles }\end{array}$ & $M$ & \multicolumn{2}{c}{ Water-based ferrofluids } \\
\cline { 3 - 4 } $\mathrm{Fe}_{3} \mathrm{O}_{4}$ & 0 & 1.119649602 & Second Solution \\
& 0.5 & 1.333048294 & -0.412911056 \\
& 1 & 1.493337918 & -1.041749204 \\
$\mathrm{CoFe}_{2} \mathrm{O}_{4}$ & 0 & 1.090512657 & -1.514815733 \\
& 0.5 & 1.305552292 & -0.375584219 \\
& 1 & 1.465834308 & -0.993386724 \\
$\mathrm{Mn}^{-Z n F e} \mathrm{Zn}_{4}$ & 0 & 1.08976403 & -1.454298252 \\
& 0.5 & 1.002688264 & -0.374640861 \\
& 1 & 1.465129036 & -0.99216224 \\
\hline
\end{tabular}


Table 4

Values of $\mathrm{Re}_{x}^{-1 / 2} N u_{x}$ with different values of $M$

\begin{tabular}{llcc}
\hline $\begin{array}{l}\text { Magnetic } \\
\text { nanoparticles }\end{array}$ & $M$ & \multicolumn{2}{c}{ Water-based ferrofluids } \\
\cline { 3 - 4 } $\mathrm{Fe}_{3} \mathrm{O}_{4}$ & 0 & 11.62577480 & Second Solution \\
& 0.5 & 11.64393334 & 11.45702035 \\
& 1 & 11.65675332 & 11.36790796 \\
$\mathrm{CoFe}_{2} \mathrm{O}_{4}$ & 0 & 12.33495424 & 11.24915198 \\
& 0.5 & 12.35264091 & 12.18251108 \\
& 1 & 12.36506264 & 12.10275686 \\
$\mathrm{Mn}-\mathrm{ZnFe}_{2} \mathrm{O}_{4}$ & 0 & 12.20291839 & 12.01066765 \\
& 0.5 & 12.22075634 & 12.04894697 \\
& 1 & 12.23327434 & 11.96794742 \\
\hline
\end{tabular}

Figures 8-13 show the profiles of velocity and temperature of magnetite ferroparticles related with the magnetic $M$ at $\lambda 0.5,1,1.5$ when $\varphi=0.1, S=2$ and $\operatorname{Pr}=6.2$. Figures 8-13 indicate increasing of $M$, decreasing the velocity profiles and rising in the temperature profiles. Because of the magnetic parameter $M$, the boundary layer's thickness becomes thinner in the first result and then thicker in the next result for all the velocity profiles and temperature profiles displayed. The temperature also increases along with the reduction of heat movement. Physically, an increase in $\varphi$ enhances the thermal conductivity of the fluid and this will help to enhance the momentum and thermal boundary layer thickness.

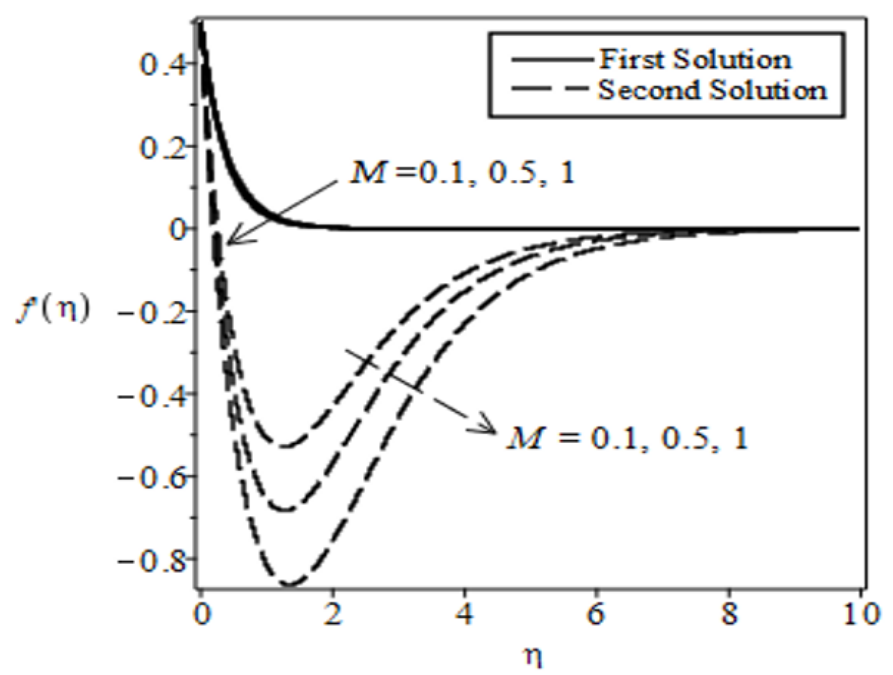

Figure 8 . Velocity profiles for various values of $M$ for magnetite at $\lambda=0.5$. 


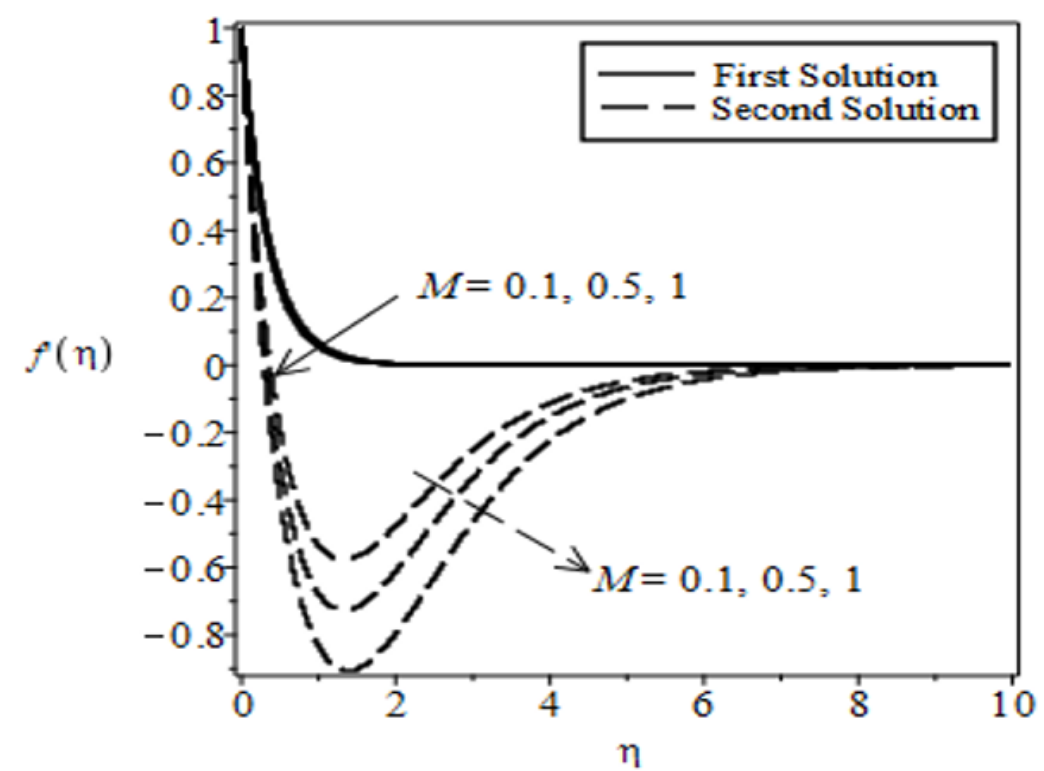

Figure 9. Velocity profiles for various values of $M$ for magnetite at $\lambda=1$.

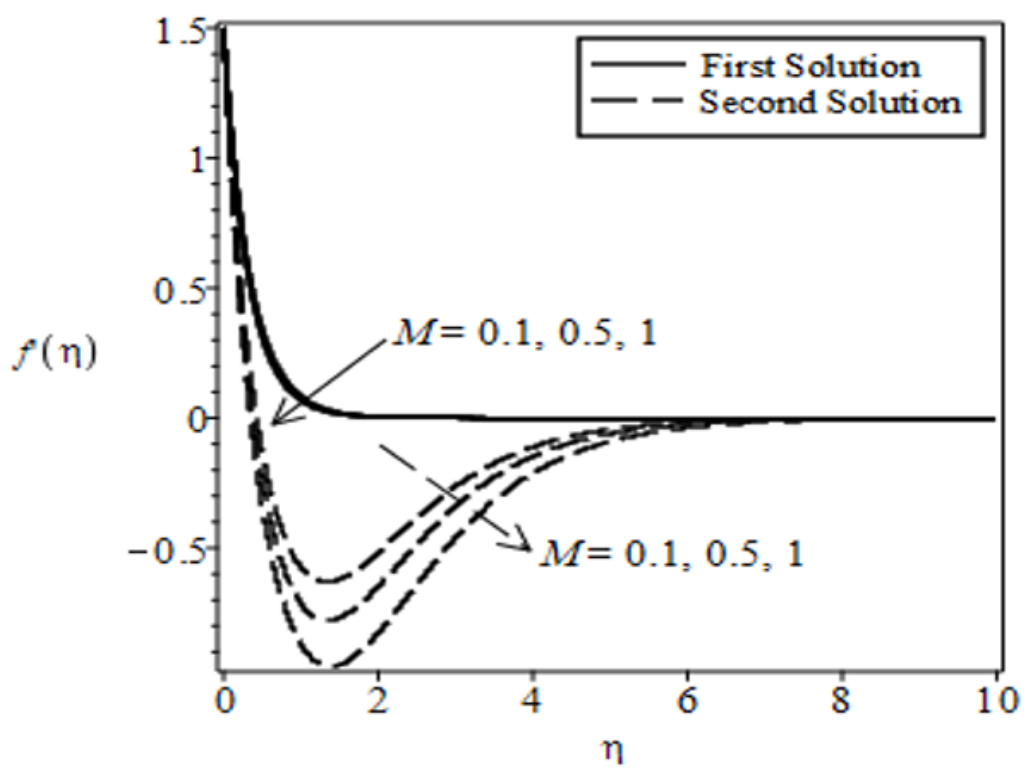

Figure 10. Velocity profiles for various values of $M$ for magnetite at $\lambda=1.5$. 


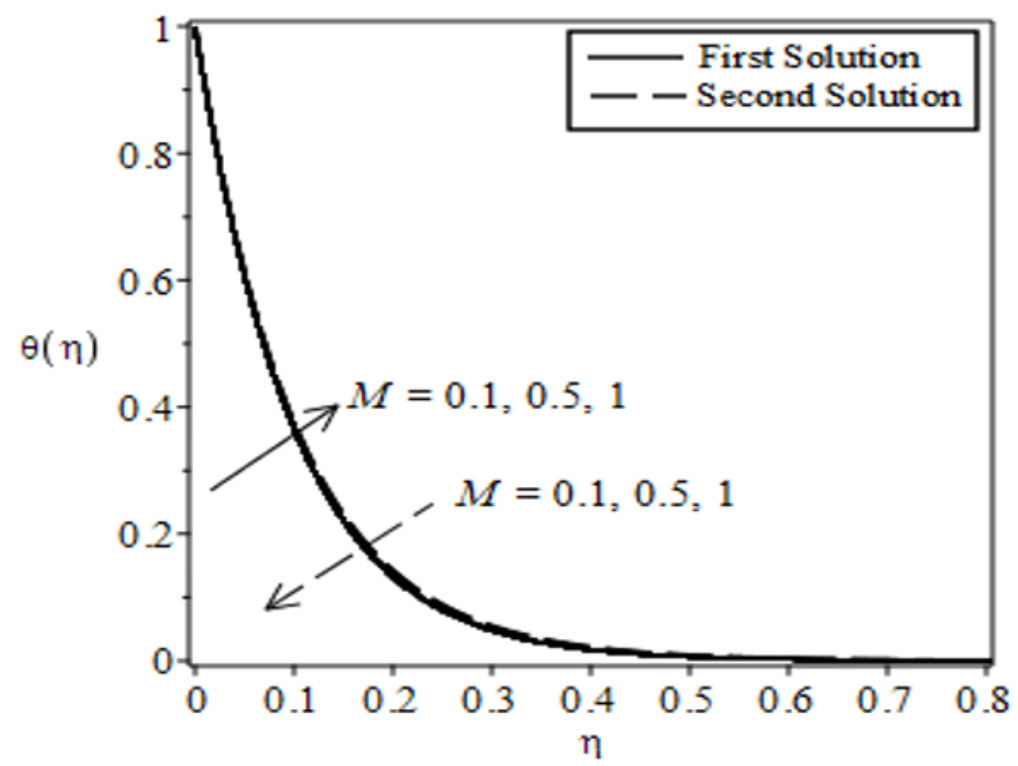

Figure 11. Temperature profiles for various values of $M$ for magnetite at $\lambda=0.5$.

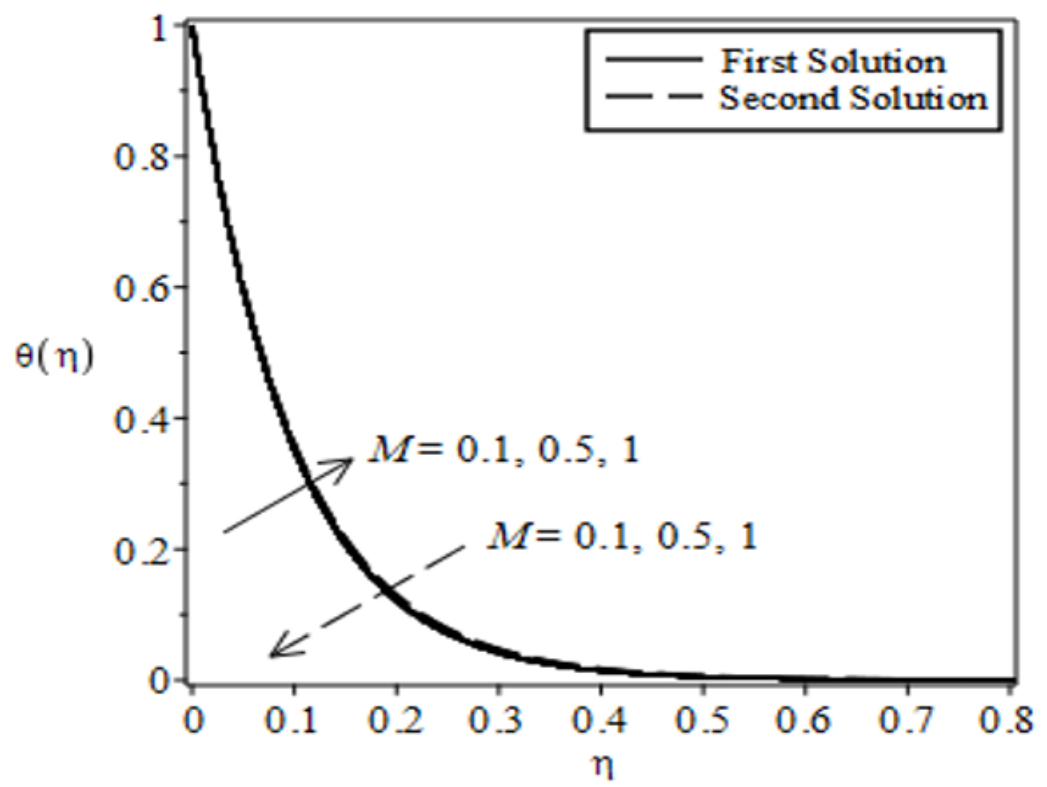

Figure 12. Temperature profiles for various values of $M$ for magnetite at $\lambda=1$. 


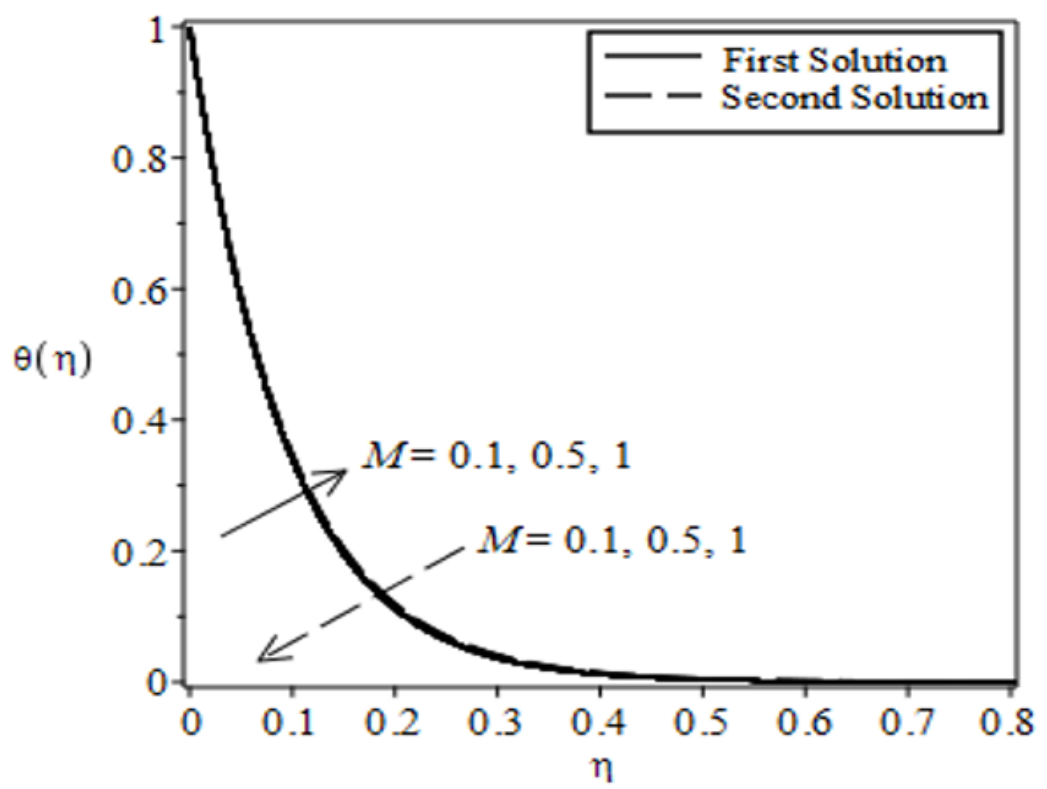

Figure 13. Temperature profiles for various values of $M$ for magnetite at $\lambda=1.5$.

\section{CONCLUSION}

In this study, we focused on a model of Tiwari and Das (2007) under some of assumptions and problem's considerations which are steady, laminar, two-dimensional boundary layer flow of an incompressible ferrofluids and transmission of heat over an exponentially stretching/shrinking sheet. The main purpose of this study to analyze the effect of chosen parameters which are magnetic parameter $M$, wall mass transfer parameter $S$, stretching/ shrinking parameter $\lambda$ and volume fraction of solid ferroparticle $\varphi$ on dimensionless physical quantities. A brief of summary conclusions drawn from the analysis are two solutions exist for both stretching/shrinking sheet up to a critical value where the presence of solutions relying upon the values of parameters considered as suction $(S>1)$, stretching/shrinking $(\lambda<0) /(\lambda>0)$, magnetic $(M>0)$ and ferroparticle volume fraction $(0 \leq \varphi \leq 0.2)$. The results displayed increasing in the skin friction caused reduction in the rate of heat motion at layer. We observed magnetite $\left(\mathrm{Fe}_{3} \mathrm{O}_{4}\right)$ has the highest number of skin friction compared to cobalt ferrite $\left(\mathrm{CoFe}_{2} \mathrm{O}_{4}\right)$ and manganese-zinc ferrite $\left(\mathrm{Mn}-\mathrm{ZnFe}_{2} \mathrm{O}_{4}\right)$ in shrinking case, while $\mathrm{CoFe}_{2} \mathrm{O}_{4}$ has the highest value of local Nusselt number. Besides, the high temperature in the boundary layer because of reduction in velocity profiles and the decrease in velocity profiles due to higher number in the magnetic parameter, which slowed the fluids motion in the boundary layer. Lastly, the rate for heat transfer declined when increasing in temperature profiles with the presence of magnetic field. 


\section{ACKNOWLEDGEMENT}

Thank you to Universiti Sains Malaysia for funding this interesting research, grant number 304/PMATHS/6315383.

\section{REFERENCES}

Alavi, S. Q., Hussanan, A., Kasim, A. R. M., Rosli, N., \& Salleh, M. Z. (2017). MHD stagnation point flow towards an exponentially stretching sheet with prescribed wall temperature and heat flux. International Journal of Applied and Computational Mathematics, 3(4), 3511-3523. https://doi.org/10.1007/s40819017-0312-x

Bachok, N., Ishak, A., \& Pop, I. (2012). Boundary layer stagnation-point flow and heat transfer over an exponentially stretching/shrinking sheet in a nanofluid. International Journal of Heat and Mass Transfer, 55(25-26), 8122-8128. https://doi.org/10.1016/j.ijheatmasstransfer.2012.08.051

Bhattacharyya, K. (2011). Boundary layer flow and heat transfer over an exponentially shrinking sheet. Chinese Physics Letters, 28(7), Article 074701. https://doi.org/10.1088/0256-307X/28/7/074701

Bhattacharyya, K., \& Layek, G. C. (2014). Magnetohydrodynamic boundary layer flow of nanofluid over an exponentially stretching permeable sheet. Physics Research International, 2014, Article 592536. https:// doi.org/10.1155/2014/592536

Bhattacharyya, K., \& Pop, I. (2011). MHD boundary layer flow due to an exponentially shrinking sheet. Magnetohydrodynamics, 47(4), 337-344. https://doi.org/10.22364/mhd.47.4.2

Bhattacharyya, K., \& Vajravelu, K. (2012). Stagnation-point flow and heat transfer over an exponentially shrinking sheet. Communications in Nonlinear Science and Numerical Simulation, 17(7), 2728-2734. https://doi.org/10.1016/j.cnsns.2011.11.011

Blaney, L. (2007). Magnetite (Fe3O4): Properties, synthesis, and applications. Leheight Preserve, 15, 33-81.

Choi, S. U., \& Eastman, J. A. (1995). Enhancing thermal conductivity of fluids with nanoparticles (No. ANL/ MSD/CP-84938; CONF-951135-29). Argonne National Lab.

Ishak, A. (2011). MHD boundary layer flow due to an exponentially stretching sheet with radiation effect. Sains Malaysiana, 40(4), 391-395.

Jusoh, R., Nazar, R., \& Pop, I. (2018). Magnetohydrodynamic rotating flow and heat transfer of ferrofluid due to an exponentially permeable stretching/shrinking sheet. Journal of Magnetism and Magnetic Materials, 465, 365-374. https://doi.org/10.1016/j.jmmm.2018.06.020

Khan, W. A., Khan, Z. H., \& Haq, R. U. (2015). Flow and heat transfer of ferrofluids over a flat plate with uniform heat flux. The European Physical Journal Plus, 130(4), 1-10. https://doi.org/10.1140/epjp/ i2015-15086-4

Magyari, E., \& Keller, B. (1999). Heat and mass transfer in the boundary layers on an exponentially stretching continuous surface. Journal of Physics D: Applied Physics, 32(5), Article 577. https://doi. org/10.1088/0022-3727/32/5/012 
Mansur, S., Ishak, A., \& Pop, I. (2015). The magnetohydrodynamic stagnation point flow of a nanofluid over a stretching/shrinking sheet with suction. PLoS One, 10(3), Article e0117733. https://doi.org/10.1371/ journal.pone. 0117733

Mohamed, M. K. A., Ismail, N. A., Hashim, N., Shah, N. M., \& Salleh, M. Z. (2019). MHD slip flow and heat transfer on stagnation point of a magnetite $(\mathrm{Fe} 3 \mathrm{O} 4)$ ferrofluid towards a stretching sheet with Newtonian heating. CFD Letters, 11(1), 17-27.

Muthtamilselvan, M., Kandaswamy, P., \& Lee, J. (2010). Heat transfer enhancement of copper-water nanofluids in a lid-driven enclosure. Communications in Nonlinear Science and Numerical Simulation, 15(6), 15011510. https://doi.org/10.1016/j.cnsns.2009.06.015

Nadeem, S., Haq, R. U., \& Khan, Z. H. (2014). Heat transfer analysis of water-based nanofluid over an exponentially stretching sheet. Alexandria Engineering Journal, 53(1), 219-224. https://doi.org/10.1016/j. aej.2013.11.003

Naramgari, S., \& Sulochana, C. (2016). MHD flow over a permeable stretching/shrinking sheet of a nanofluid with suction/injection. Alexandria Engineering Journal, 55(2), 819-827. https://doi.org/10.1016/j. aej.2016.02.001

Noghrehabadi, A., Ghalambaz, M., Izadpanahi, E., \& Pourrajab, R. (2014). Effect of magnetic field on the boundary layer flow, heat, and mass transfer of nanofluids over a stretching cylinder. Journal of Heat and Mass Transfer Research, 1(1), 9-16. https://doi.org/10.22075/JHMTR.2014.149

Odenbach, S. (2003). Ferrofluids-magnetically controlled suspensions. Colloids and Surfaces A: Physicochemical and Engineering Aspects, 217(1-3), 171-178. https://doi.org/10.1016/S0927-7757(02)00573-3

Rahman, N. H. A., Bachok, N., \& Rosali, H. (2019). MHD stagnation point flow over a stretching/ shrinking sheet in nanofluids. Universal Journal of Mechanical Engineering, 7(4), 183-191. https://doi.org/ 10.13189/ujme.2019.070406

Ramli, N., Ahmad, S., \& Pop, I. (2018). MHD forced convection flow and heat transfer of ferrofluids over a moving at plate with uniform heat flux and second-order slip effects. Scientia Iranica, 25(4), 2186-2197. https://doi.org/10.24200/SCI.2017.4343

Shokrollahi, H. (2013). Structure, synthetic methods, magnetic properties and biomedical applications of ferrofluids. Materials Science and Engineering C, 33(5), 2476-2487. https://doi.org/10.1016/j. msec.2013.03.028

Tiwari, R. K., \& Das, M. K. (2007). Heat transfer augmentation in a two-sided lid-driven differentially heated square cavity utilizing nanofluids. International Journal of heat and Mass transfer, 50(9-10), 2002-2018. https://doi.org/10.1016/j.ijheatmasstransfer.2006.09.034 
